\title{
REVIEW
}

\section{A Review of Novel Anticoagulants}

\author{
Jordan A Green MD', Stephen Couban MD', David Anderson MD', Sudeep Shivakumar MD'1 \\ ${ }^{1}$ Division of Hematology, Department of Medicine, Dalhousie University; Halifax, Nova Scotia, Canada
}

\begin{abstract}
The well-established indications for anticoagulant therapy include atrial fibrillation, venous thromboembolism (VTE) and mechanical heart valves. Vitamin $\mathrm{K}$ antagonists are the most common anticoagulants used in the outpatient setting. Two new classes of anticoagulants (direct thrombin and factor Xa inhibitors) have shown promise as alternatives to the vitamin $\mathrm{K}$ antagonists. Specifically, dabigatran, rivaroxaban and apixaban have been studied in comparison to warfarin for their use in preventing systemic stroke/embolism in patients with atrial fibrillation and for managing the recurrence of VTE. This article will review the literature on the efficacy of these agents, as well as the benefits and disadvantages of their use.
\end{abstract}

The well-established indications for anticoagulant therapy include atrial fibrillation, venous thromboembolism (VTE) and mechanical heart valves. ${ }^{1,2,3}$ The most common anticoagulants used in the outpatient setting are vitamin $\mathrm{K}$ antagonists, such as warfarin. Warfarin disrupts vitamin $\mathrm{K}$ metabolism by inhibiting the carboxylation of vitamin-K dependent coagulation factors (II, VII, IX and X), rendering them inactive in the coagulation pathway. ${ }^{4}$

Warfarin is administered orally, compared to unfractionated and low molecular weight heparin, which must be administered parenterally. Its anticoagulant effect can be reversed by administration of vitamin $\mathrm{K}$ or prothrombin complex concentrates. ${ }^{5}$ Disadvantages associated with the use of warfarin include the need for frequent laboratory monitoring and its interactions with foods and many common medications such as antibiotics. ${ }^{6}$ As with all anticoagulants, there is a risk of bleeding, including major hemorrhage. ${ }^{7}$
Given these issues, there is a need to find alternative oral anticoagulants that are more convenient, more effective, and safer than warfarin.

\section{Novel Anticogulants}

Two new classes of anticoagulants have shown promise as alternatives to the vitamin $\mathrm{K}$ antagonists (Table 1). Dabigatran, a specific competitive inhibitor of thrombin, was the first oral thrombin inhibitor to be approved and marketed. Approximately $80 \%$ of dabigatran is excreted renally and it has a half-life of 12-17 hours. ${ }^{8}$ Two other novel oral anticoagulants are rivaroxaban and apixaban, which are factor Xa inhibitors. Rivaroxaban has a half-life of 7-11 hours and is excreted unchanged by the kidneys and converted to inactive metabolites by the liver. ${ }^{9}$ Apixaban has a half-life of 8-15 hours and is eliminated both by the kidneys and the gastrointestinal tract. ${ }^{9}$ Due to the predictable pharmacokinetic profiles of these agents, they do not require routine coagulation monitoring. ${ }^{8,9}$
Table 1. Novel anticoagulants.

\begin{tabular}{|c|c|c|c|}
\hline Drug & MOA & KINETICS & $\begin{array}{l}\text { PIVOTAL } \\
\text { TRIALS }\end{array}$ \\
\hline Dabigatran & $\begin{array}{l}\text { Direct thrombin } \\
\text { inhibitor }\end{array}$ & $\begin{array}{l}\mathrm{t}_{1 / 2}=12-17 \mathrm{hrs}^{8} \\
\text { Excretion }=\text { Renal }^{8}\end{array}$ & $\begin{array}{l}\text { RE-LY' } \\
\text { RE-COVER }\end{array}$ \\
\hline Rivaroxaban & $\begin{array}{l}\text { Factor Xa } \\
\text { inhibitor }\end{array}$ & $\begin{array}{l}\mathrm{t}_{1 / 2}=7-11 \mathrm{hrs}^{9} \\
\text { Excretion }=\text { Renal } / \text { Hepatic }^{9}\end{array}$ & $\begin{array}{l}\text { EINSTEIN }{ }^{12} \\
\text { ROCKET-AF }\end{array}$ \\
\hline Apixaban & $\begin{array}{l}\text { Factor Xa } \\
\text { inhibitor }\end{array}$ & $\begin{array}{l}\mathrm{t}_{1 / 2}=8-15 \mathrm{hrs}^{9} \\
\text { Excretion }=\text { Renal } / \mathrm{Gl}^{9}\end{array}$ & $\begin{array}{l}\text { ARISTOTLE }{ }^{14} \\
\text { AVERROES }^{15}\end{array}$ \\
\hline
\end{tabular}

\section{Dabigatran}

Dabigatran was studied in a trial of 18,113 patients with atrial fibrillation and at least one additional risk factor for stroke. Risk factors included a previous stroke or transient ischemic attack, age ( $>75$ or 65-74 plus coronary artery disease, diabetes mellitus or hypertension), New York Heart Association Class II or higher symptoms of heart failure within the previous 6 months, and a left ventricular 
ejection fraction $<40 \% .{ }^{10}$ The study, published as the RE-LY trial, randomized patients to one of three groups: dose-adjusted warfarin (to achieve an INR of 2.0-3.0), dabigatran $110 \mathrm{mg}$ twice daily or dabigatran $150 \mathrm{mg}$ twice daily. The primary outcome of the study was stroke or systemic embolism. In their study, it was shown that patients randomized to the dabigatran $150 \mathrm{mg}$-group had lower rates of stroke and systemic embolism compared to those randomized to the warfarin group (yearly occurrence rates: $1.11 \%$ vs. $1.69 \%$, respectively; $\mathrm{p}<0.001$ ), with similar rates of major hemorrhage $(3.11 \%$ per year vs. $3.36 \%$ per year, respectively; $\mathrm{p}=0.31) .{ }^{10}$ Patients in the dabigatran 110 mg-group had similar rates of stroke and systemic embolism as warfarin, with lower rates of major bleeding ( $2.71 \%$ vs. $3.36 \%$, respectively; $\mathrm{p}=0.003) .{ }^{10}$ The rate of hemorrhagic stroke was reduced in both the dabigatran $110 \mathrm{mg}$ and $150 \mathrm{mg}$ groups as compared to warfarin $(0.12 \%$ and $0.10 \%$ vs. $0.38 \%$, respectively; $\mathrm{p}<0.001) .{ }^{10}$ Other measured outcomes included rate of death and myocardial infarction. The rate of death for warfarin was $4.13 \%$ per year, compared to $3.75 \%$ per year for the $110 \mathrm{mg}$ dabigatran arm $(\mathrm{p}=0.13)$ and $3.64 \%$ per year for the dabigatran $150 \mathrm{mg}$ arm ( $\mathrm{p}=$ 0.051)..$^{10}$ The yearly event rate of myocardial infarction for warfarin was $0.53 \%$. Rates were higher in both the dabigatran $110 \mathrm{mg}(0.72 \%$ per year, $\mathrm{p}=0.07)$ and 150 mg groups $(0.74 \%, \mathrm{p}=0.048) .{ }^{10}$

In the RE-COVER trial, dabigatran was compared to warfarin in the treatment of patients with acute VTE. In this study, 2564 patients with acute VTE were treated with a parenteral anticoagulant for a median of 9 days and then randomized to receive either dose-adjusted warfarin (to achieve an INR of 2.0-3.0) or dabigatran 150 mg twice daily. The primary outcome was recurrence of VTE at six months. The results showed that dabigatran was as effective as warfarin in preventing recurrent VTE (recurrence rates $2.4 \%$ vs. $2.1 \%$, respectively; $\mathrm{p}$ $<0.001) .{ }^{11}$ Episodes of major and non-major bleeding were similar between groups. ${ }^{11}$

\section{Rivaroxaban}

Rivaroxaban, a factor Xa inhibitor, has been evaluated for the treatment of acute deep vein thrombosis (DVT). In an open-label randomized study of 3449 patients (EINSTEIN trial), rivaroxaban (15 mg twice daily for 2 weeks followed by $20 \mathrm{mg}$ once daily) alone was compared to standard therapy (enoxaparin followed by a vitamin $\mathrm{K}$ antagonist). The results demonstrated that rivaroxaban was as effective as standard therapy at preventing recurrent VTE in the study period (event rate $2.1 \%$ vs. $3.0 \%$, respectively; $\mathrm{p}<0.001) .{ }^{12}$ The principal safety outcome of major bleeding or non-major clinically relevant bleeding was equal between both groups. ${ }^{12}$ A follow-up study of 1196 patients compared rivaroxaban with placebo for VTE prevention after patients had received a minimum three-month course of anticoagulation. The results demonstrated that rivaroxaban reduced the recurrence rate of VTE by $82 \%$ as compared to placebo (recurrence rate $1.3 \%$ vs. $7.1 \%$, respectively; $\mathrm{p}<0.001) .{ }^{12}$ There was an increased risk for non-major bleeding in the rivaroxaban group $(5.4 \%$ vs. $1.2 \%$ placebo). ${ }^{12}$ As well, four patients receiving rivaroxaban had non-fatal major bleeding, compared to none in the placebo group $(\mathrm{p}=0.11) .{ }^{12}$

Rivaroxaban has also been evaluated in patients with nonvalvular atrial fibrillation. The ROCKET-AF study was a double-blind randomized trial of 14,264 patients with atrial fibrillation at increased risk of stroke. Patients were randomized to receive rivaroxaban $20 \mathrm{mg}$ daily or dose-adjusted warfarin (to achieve INR of 2.0-3.0). As in the RE-LY trial, the primary outcome was stroke and systemic embolism. The results demonstrated rivaroxaban to be as efficacious as adjusted dose warfarin in preventing stroke and systemic embolism (yearly occurrence rates: $1.7 \%$ vs. $2.2 \%$, respectively; p $<0.001) .{ }^{13}$ As well, there were no differences between the two groups in major and clinically significant non-major bleeding. ${ }^{13}$ The rivaroxaban group had less intracranial $(0.5 \%$ vs. $0.7 \%$; $=0.02)$ and fatal bleeding $(0.2 \%$ vs. $0.5 \%$; $p=0.003) .{ }^{13}$ Major gastrointestinal bleeding and bleeding requiring transfusion was more common in patients who received rivaroxaban (3.2\% vs. $2.2 \% ; \mathrm{p}<0.001) .{ }^{13}$

\section{Apixaban}

Another factor Xa inhibitor, apixaban, has been studied in comparison to warfarin in patients with atrial fibrillation and at least one additional risk factor for stroke. In the double-blinded ARISTOLE study, 18,201 patients were randomized to receive dose-adjusted warfarin or apixaban $5 \mathrm{mg}$ twice daily. Patients receiving apixaban had a lower rate of stroke and systemic embolism than those on warfarin (yearly occurrence rate: $1.27 \%$ vs. $1.60 \%$, respectively; $\mathrm{p}<0.001$ for non-inferiority; $\mathrm{p}=0.001$ for superiority). ${ }^{14}$ As well, the apixaban study group had both lower rates of major bleeding (2.13\% vs. 3.09\%; p < 0.001) and mortality (3.52\% vs. $3.94 \% ; \mathrm{p}=0.047)$ compared to the warfarin group. ${ }^{14}$

Apixaban has also been studied in comparison to aspirin in the prevention of stroke and systemic embolism. In the AVERROES trial, 5599 patients with atrial fibrillation and an increased risk for stroke, who were unsuitable candidates for vitamin $\mathrm{K}$ antagonists, 
were randomized to receive either aspirin or apixaban. The study was terminated early due to a clear benefit in the apixaban group. The number of primary outcome events (stroke and systemic embolism) in the apixaban group was 51 (1.6\% per year), compared to 113 in the aspirin group $(3.7 \%$ per year; $\mathrm{p}<0.001) .{ }^{15}$ There was no increased risk for major hemorrhage or intracranial bleeding in the apixaban group. ${ }^{15}$

\section{Monitoring \& Reversal}

Unlike traditional anticoagulants such as heparin or warfarin, the novel agents do not usually require laboratory monitoring. However, coagulation assessment may be warranted in certain situations including drug overdose, in episodes of severe bleeding or if urgent surgical procedures are required. ${ }^{16}$

The effect of these novel anticoagulants on traditional coagulation assays is unknown. The plasma concentration of dabigatran is variable between patients based on their age, dose, absorption and renal clearance. ${ }^{17} \mathrm{~A}$ recent study demonstrated that at maximum plasma concentration, most patients taking dabigatran had a prolonged activated thromboplastin time (APTT). ${ }^{17}$ A second study demonstrated that the anti-Xa level and the aPTT are affected by rivaroxaban. ${ }^{16}$ The effect of both drugs on other coagulation tests such as prothrombin time (PT), fibrinogen, antithrombin and activated protein $\mathrm{C}$ (APC) resistance assays were less predictable. ${ }^{6,17}$ Standardized readily available assays for monitoring any of the novel oral agents have not yet been developed for routine practice.

Currently there is no antidote for direct thrombin and factor Xa inhibitors and the efficacy of reversal agents has not been extensively studied in humans. In a recent small study of 12 healthy males, administration of prothrombin complex concentrate (PCC) was shown to completely and immediately reverse the anticoagulant effect of rivaroxaban. However, it had no effect on dabigatran. ${ }^{18}$ Whether $\mathrm{PCC}$ administration reduces the risk of bleeding associated with rivaroxaban is unknown.

\section{Conclusion}

Novel anticoagulants including dabigatran, rivaroxaban and apixaban offer an alternative to traditional agents such as warfarin (Table 2). Recent studies demonstrate that these agents are as efficacious as warfarin in treating patients with atrial fibrillation and VTE. ${ }^{10-14}$ In some instances, studies have demonstrated the superiority of these agents compared to warfarin, such as in the use of dabigatran for the prevention of stroke and systemic embolism in patients with atrial fibrillation. ${ }^{10}$ As well, apixaban has been shown to be superior to aspirin in patients with atrial fibrillation who are unable to take vitamin $\mathrm{K}$ antagonists. ${ }^{15}$ Moreover, given the stable pharmacokinetics of these anticoagulants, they do not require coagulation monitoring and dosing adjustments, making their use more convenient for patients and practitioners. ${ }^{8,9}$ Finally, a recent study examining the use and cost of dabigatran in Canada determined that it is a more cost-effective approach to preventing stroke and systemic embolism than warfarin. ${ }^{19}$

Despite their many benefits, these novel medications are not without risk. For instance, there is little research on the most appropriate and consistent method of laboratory monitoring, which is important in specific

Table 2: A comparison of warfarin, dabigatran and rivaroxaban

\begin{tabular}{|c|c|c|c|c|c|}
\hline Drug & MOA & KINETICS & $\mathrm{cosT}^{+}$ & $\begin{array}{l}\text { SPECIFIC } \\
\text { ANTIDOTE }\end{array}$ & $\begin{array}{l}\text { STANDARD } \\
\text { LABORATORY } \\
\text { TESTING }\end{array}$ \\
\hline Warfarin & $1.69-2.2 \%^{10,13}$ & $3.36-3.4 \%^{10,13}$ & $\$ 0.01 / d$ & Vitamin $\mathrm{K}$ & INR \\
\hline \multirow[t]{2}{*}{ Dabigatran } & $\begin{array}{l}150 \mathrm{mg}=1.11 \% \\
(p<0.001)^{10}\end{array}$ & $\begin{array}{l}150 \mathrm{mg}=3.11 \% \\
(p=0.31)^{10}\end{array}$ & $\$ 3.20 / d$ & No & No \\
\hline & $\begin{array}{l}110 \mathrm{mg}=1.53 \% \\
(p=0.34) 10\end{array}$ & $\begin{array}{l}110 \mathrm{mg}=2.71 \% \\
(p=0.003)^{10}\end{array}$ & & & \\
\hline Rivaroxaban & $1.7 \%(p<0.001)^{13}$ & $3.6 \%(p=0.58)^{13 v}$ & $\$ 2.84 / d$ & No & No \\
\hline
\end{tabular}


circumstances such as acute bleeding. As well, unlike warfarin there is no specific antidote and the most appropriate type and dosage of reversal agents has not been extensively studied. Furthermore, the use of reversal agents such as PCC in lieu of a specific antidote is not ideal, as blood products have their own inherent risks and associated costs.

In summary, dabigatran, rivaroxaban and apixaban are novel alternatives to traditional anticoagulants such as warfarin. As their use becomes more widespread, further research on monitoring and reversal is required.

\section{References}

1. Hart RG, Pearce LA, Aguilar MI. Meta-analysis: antithrombotic therapy to prevent stroke in patients who have nonvalvular atrial fibrillation. Ann Intern Med 2007;146(12):857-867.

2. Kearon C, Kahn SR, Agnelli G, Goldhaber S, Raskob GE, Comerota AJ. Antithrombotic therapy for venous thromboembolic disease: American College of Chest Physicians evidence-based clinical practice guidelines (8th Edition). Chest 2008;133(6 Suppl):454S-545S.

3. Stein PD, Alpert JS, Bussey HI, Dalen JE, Turpie AG. Antithrombotic therapy in patients with mechanical and biological prosthetic heart valves. Chest 2001;119(1 Suppl):220S-227S.

4. Hirsh J, Dalen J, Anderson DR, Poller L, Bussey H, Ansell J, Deykin D. Oral anticoagulants: mechanism of action, clinical effectiveness, and optimal therapeutic range. Chest 2001;119:8S-21S.

5. Ansell J, Hirsh J, Hylek E, Jacobson A, Crowther M, Palareti G. Pharmacology and management of the vitamin $\mathrm{K}$ antagonists: American College of Chest Physicians evidence-based clinical practice guidelines (8th Edition). Chest 2008;133(6 Suppl):160S-198S.

6. Holbrook AM, Pereira JA, Labiris R, McDonald H, Douketis JD, Crowther M, Wells PS. Systematic overview of warfarin and its drug and food interactions. Arch Intern Med 2005;165(10):1095-1106.

7. Hylek EM, Evans-Molina C, Shea C, Henault LE, Regan S. Major hemorrhage and tolerability of warfarin in the first year of therapy among elderly patients with atrial fibrillation. Circulation 2007;115(21):2689-2696

8. Stangier J. Clinical pharmacokinetics and pharmacodynamics of the oral direct thrombin inhibitor dabigatran etexilate. Clin Pharmacokinet 2008;47(5):285-295

9. Bauer KA. Recent progress in anticoagulant therapy: oral direct inhibitors of thrombin and factor Xa. J Thromb Haemost 2011;9 Suppl 1:12-19.

10. Connolly SJ, Ezekowitz MD, Yusuf S, Eikelboom J, Oldgren J, Parekh A, Pogue J et al. Dabigatran versus warfarin in patients with atrial fibrillation. N Engl J Med 2009;361(12):1139-1151.

11. Schulman S, Kearon C, Kakkar AK, Mismetti P, Schellong S, Eriksson $\mathrm{H}$, Baanstra D et al. Dabigatran versus warfarin in the treatment of acute venous thromboembolism. N Engl J Med 2009;361(24):2342-2352.

12. Bauersachs $\mathrm{R}$, Berkowitz SD, Brenner $\mathrm{B}$, Buller $\mathrm{HR}$, Decousus H, Gallus AS, Lensing AW et al. Oral rivaroxaban for symptomatic venous thromboembolism. N Engl J Med 2010;363(26):2499-2510.

13. Patel MR, Mahaffey KW, Garg J, Pan G, Singer DE, Hacke W, Breithardt $\mathrm{G}$ et al. Rivaroxaban versus warfarin in nonvalvular atrial fibrillation. N Engl J Med 2011;365(10):883-891.

14. Granger CB, Alexander JH, McMurray JJ, Lopes RD, Hylek
EM, Hanna M, Al-Khalidi HR et al. Apixaban versus warfarin in patients with atrial fibrillation. N Engl J Med 2011;365(11):981-992.

15. Connolly SJ, Eikelboom J, Joyner C, Diener HC, Hart R, Golitsyn S, Flaker G. Apixaban in patients with atrial fibrillation. N Engl J Med 2011;364(9):806-817.

16. Hillarp A, Baghaei F, Fagerberg Blixter I, Gustafsson KM, Stigendal L, Sten-Linder M, Strandberg K et al. Effects of the oral, direct factor Xa inhibitor rivaroxaban on commonly used coagulation assays. J Thromb Haemost 2011;1:133-139.

17. Lindahl TL, Baghaei F, Blixter IF, Gustafsson KM, Stigendal L, Sten-Linder M, Strandberg K, Hillarp A. Effects of the oral, direct thrombin inhibitor dabigatran on five common coagulation assays. Thromb Haemost 2011;105(2):371-378.

18. Eerenberg ES, Kamphuisen PW, Sijpkens MK, Meijers JC, Buller HR, Levi M. Reversal of rivaroxaban and dabigatran by prothrombin complex concentrate: a randomized, placebocontrolled, crossover study in healthy subjects. Circulation 2011;124(14):1573-1579.

19. Sorensen SV, Kansal AR, Connolly S, Peng S, Linnehan J, Bradley-Kennedy C, Plumb JM. Cost-effectiveness of dabigatran etexilate for the prevention of stroke and systemic embolism in atrial fibrillation: a Canadian payer perspective. Thromb Haemost 2011;105(5):908-919.

\section{$\square$ HEARTLAND HEALTH REGION}

Heartland Healthy People, Healthy Communities and

Service Excellence in an Enduring Health System

\section{EXPLORE OUR OPPORTUNITIES FOR FAMILY PHYSICIANS}

People who care for and abovt one another are the heart and spirit of a community. At Heartland Health Region, our dedicated employees share in the vision of providing safe, quality and compassionate care for our clients and communities.

Heartland is located in west-central 5 ashatchewan and prevides health caee services to a population of 44,100 . Heartland is home to same of the friendliest communities in the country! We have excellemt healthcare services and programs, geat recreation and leisure services and wonderful sahools.

Come join our team today!

For further information contact: Christa Garrett

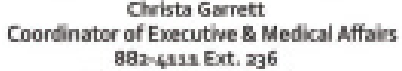
882-4131 Ext: 236 christa.garrett@hiha.sk.ca

Please visit our website for details on the positions and more great health careers that await you!

www.hrha.sk.ca 